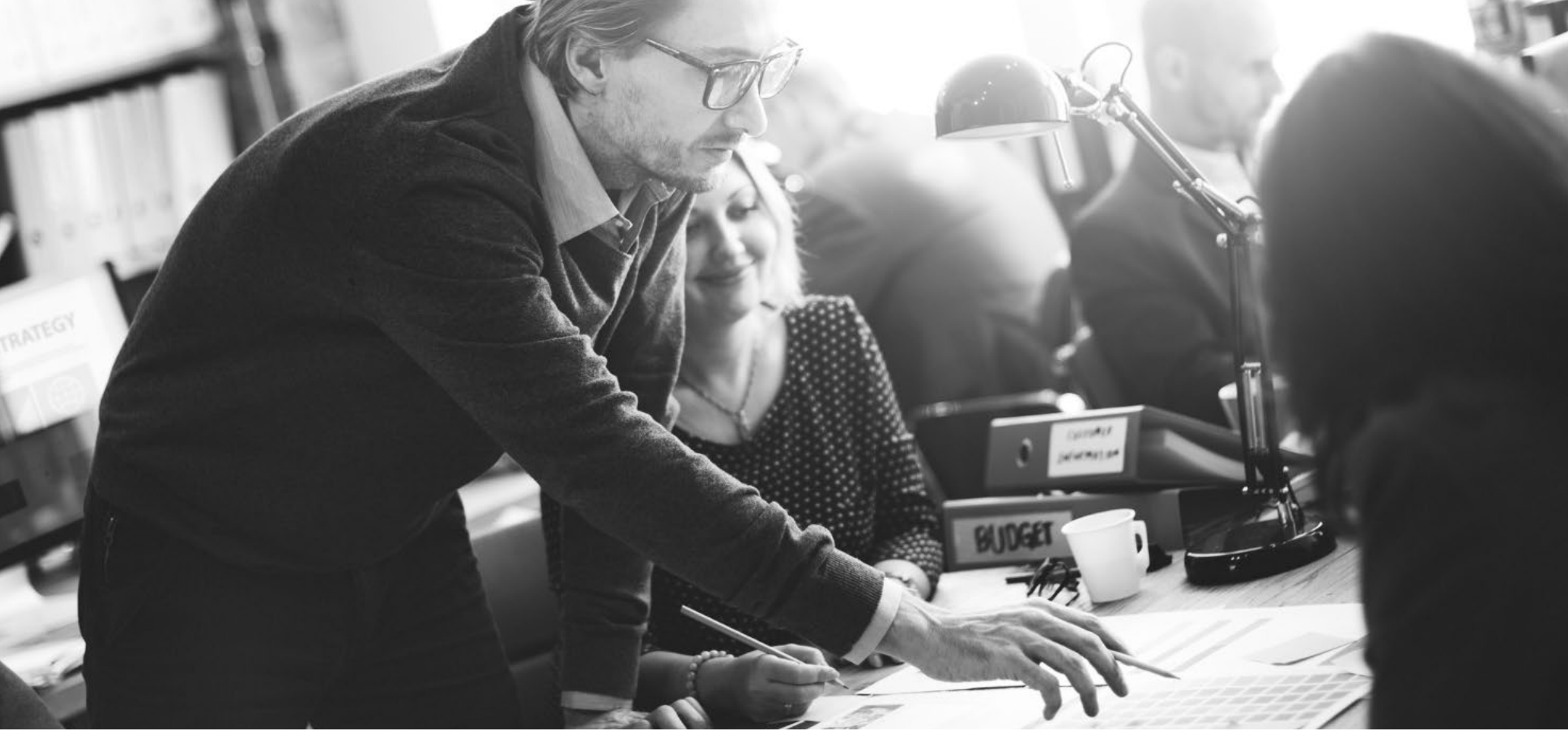

\title{
Una propuesta constitucional para garantizar un servicio civil profesional e imparcial para chile*
}

Eduardo Abarzúa C. PhD. en Ciencias del Trabajo, Universidad Católica de Lovaina, Bélgica. Decano Facultad de Economía y Negocios, Universidad Alberto Hurtado. Consejero del Consejo de Alta Direc-ción; Enrique Rajevic M. Doctor en Derecho, Universidad Carlos III de Madrid, España. Máster en Polí-tica Territorial y Urbanística, 2002, Instituto Pascual Madoz, Universidad Carlos III de Madrid, España. Director del Departamento de Derecho Público y del Postítulo en Derecho Administrativo y Gestión Pública, Universidad Alberto Hurtado.

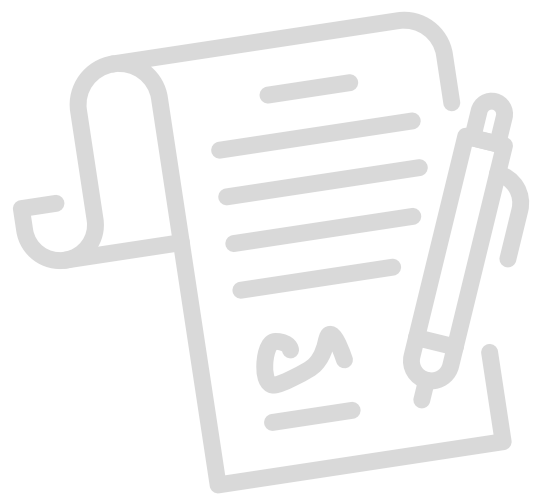

\section{Introducción}

0 bien en las últimas décadas se han logrado avances muy importantes en materia de modernización de la gestión pública y del aparato administrativo estatal, lo cierto es que en muchos ámbitos su quehacer sigue siendo deficiente. De hecho, su incapacidad para enfrentar y resolver problemas ciudadanos fue parte de los detonantes del estallido social de octubre de 2019 , y ha contribuido a la falta de equidad social y la desconfianza en las instituciones públicas.

Se trata entonces de un fenómeno que se ha ido profundizando, independiente de los gobiernos de turno. En este andar se ha demostrado la ineficacia de las normas constitucionales que, en teoría, apostaban por un modelo de carrera que ha quedado desplazado, en los hechos, por un modelo frágil e inestable que ha favorecido el clientelismo y perjudicado la continuidad de las políticas públicas más allá de cada gobierno.
La precariedad del régimen del empleo público imperante y el debilitamiento de su carácter profesional ha sido consecuencia de un diseño en el cual conviven un porcentaje limitado de funcionarios y funcionarias de planta 0 adscritos a la carrera funcionaria y una creciente mayoría a contrata. Además, en este escenario, conviven trabajadores y trabajadoras a honorarios que muchas veces desempeñan tareas permanentes, ajenas a la naturaleza de esta categoría, lo que evidencia la ausencia de un tratamiento integral y debilita la necesaria distinción entre Gobierno y Administración, con sus sinergias, complementariedades y equilibrios.

Por lo tanto, la calidad del empleo público resulta crítica tanto para hacer frente a la complejidad que ha alcanzado la gestión del Estado y su necesaria continuidad, como también para reducir la brecha que existe entre las demandas ciudadanas y la capacidad de los agentes públicos para satisfacerlas. 
Y es, precisamente, el proceso constituyente en curso el que ofrece una oportunidad inmejorable para concordar nuevos y, esta vez, eficaces criterios respecto del tratamiento constitucional del empleo público.

La propuesta comprende tres principios constitucionales: consagrar el carácter profesional y técnico de la Administración Públi$\mathrm{ca}$, reconociendo tres estamentos al interior del Ejecutivo; garantizar el acceso igualitario al empleo público; y reconocer los derechos colectivos (sindicalización, negociación colectiva y huelga) de las y los trabajadores del Estado.

\section{Nítida distinción entre el rol del gobierno y de la administración pública}

En línea con el denominado derecho a una buena Administración Pública, la nueva Constitución Política debería garantizar una Administración Pública profesional y técnica, que contribuya a mejorar la calidad de los servicios públicos, al buen trato a las personas y a la continuidad de las políticas de Estado. Para ello resulta esencial que se establezca una nítida distinción entre Gobierno y Administración.

Siendo así, al Presidente(a) de la República le correspondería la conducción general del Estado, a través del Gobierno y la Administración, que son complejos organizativos diferentes pues tienen roles diferentes, como se pasa a explicar:

a. Gobierno: Es el responsable de la conducción política del Estado y de la definición de políticas públicas, siendo encabezado -bajo la forma de gobierno que rige hasta hoy- por la persona que ejerza la Presidencia de la República e integrándolo ministros(as), subsecretarios(as), delegados(as) presidenciales y personal de exclusiva confianza, quienes ejercen la dirección política.

b. Administración Pública: Es la responsable de implementar las políticas públicas definidas por el Gobierno y, además, de proveer a la ciudadanía de servicios públicos en forma directa, continua y per- manente. El Presidente(a) de la República contará con la colaboración de quienes ejerzan cargos directivos y personas funcionarias, que no serán de exclusiva confianza y cuya forma de nombramiento y remoción será definida por ley. La integran personal directivo y personas funcionarias, que constituyen el Servicio Civil. La ley debe demandar al personal directivo público y a las personas funcionarias, el ejercicio imparcial, objetivo y políticamente prescindente de la función pública.

Además, debe precisarse que la ley garantice que la gestión y coordinación interna de los ministerios corresponda a un cargo directivo público (no político), responsable de coordinar la acción de los órganos y servicios públicos sectoriales, supervisar su gestión y ejercer la administración interna del ministerio.

La redacción de esta propuesta constitucional reconoce tres estamentos al interior del Ejecutivo que deberán estar sujetos a un estatuto propio, definido por ley, coherente con los principios de probidad, eficiencia, eficacia, jerarquía, transparencia y coordinación, que se proyecte en deberes y derechos que protejan la dignidad de la función pública: 1) Dirección Política: Corresponde a quien ejerza la Presidencia de la República junto a autoridades y personas funcionarias de exclusiva confianza, quienes son de libre designación presidencial y deben mantenerse en sus cargos mientras cuenten con la confianza de quien ejerza la Presidencia de la República o hasta que se cumpla el período presidencial durante el cual esas personas fueron nombradas, existiendo en cada Ministerio una dotación de cargos de confianza, cuyo número, función y remuneración será definida por ley.

2) Dirección Pública: Es el grupo de directivos/as responsables de conducir las instituciones de acuerdo con las políticas públicas de cada gobierno, pero sin ser de su exclusiva confianza.

3) Personas Funcionarias: Son quienes se encargan de ejecutar y desarrollar las políticas públicas, bajo la supervisión de un/a directivo/a público/a.

Cabe insistir que en el caso de las/os directivos/as públicos/as y las personas funcionarias la propuesta establece que deberán contar con un estatuto jurídico propio, que sea

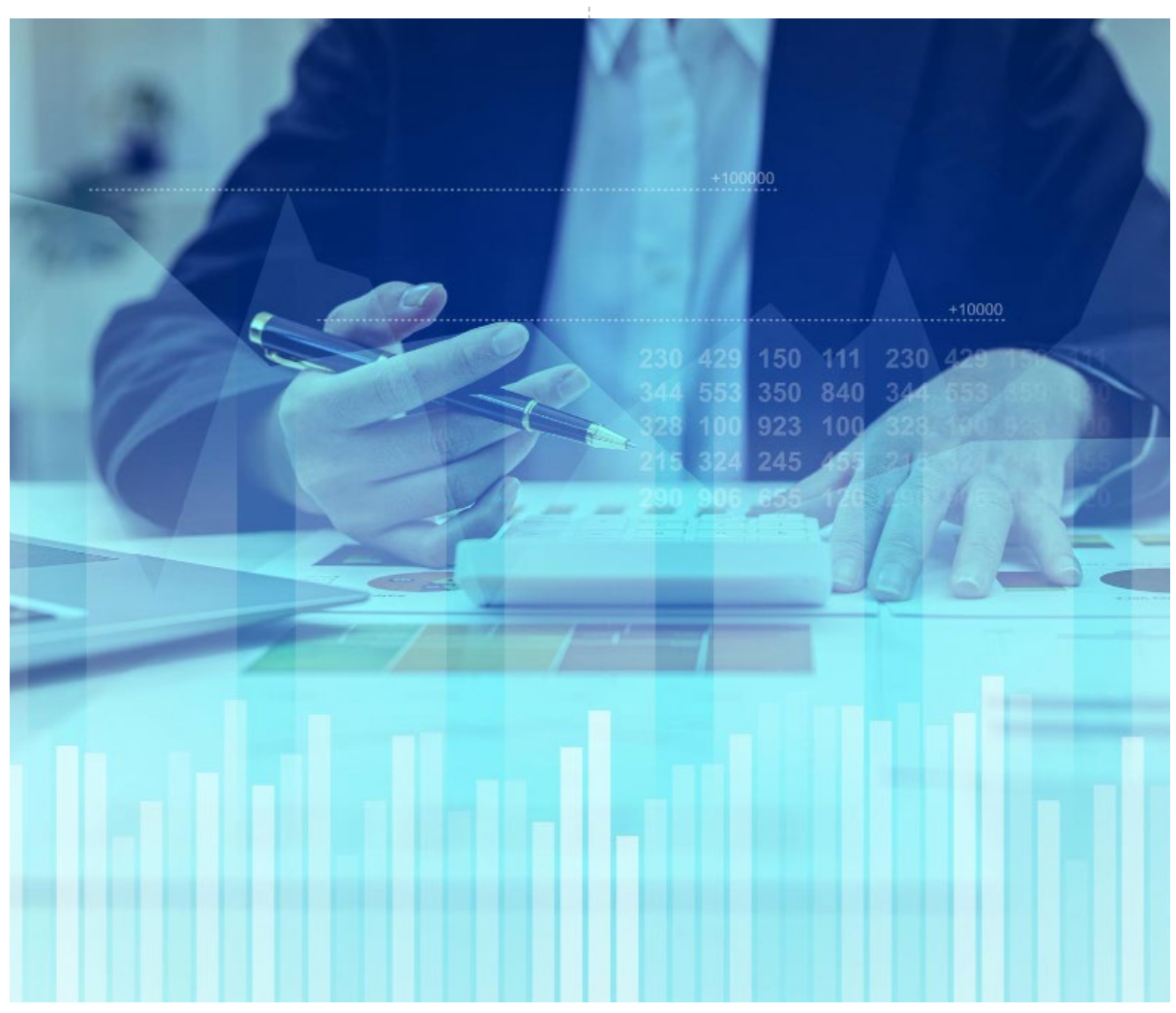




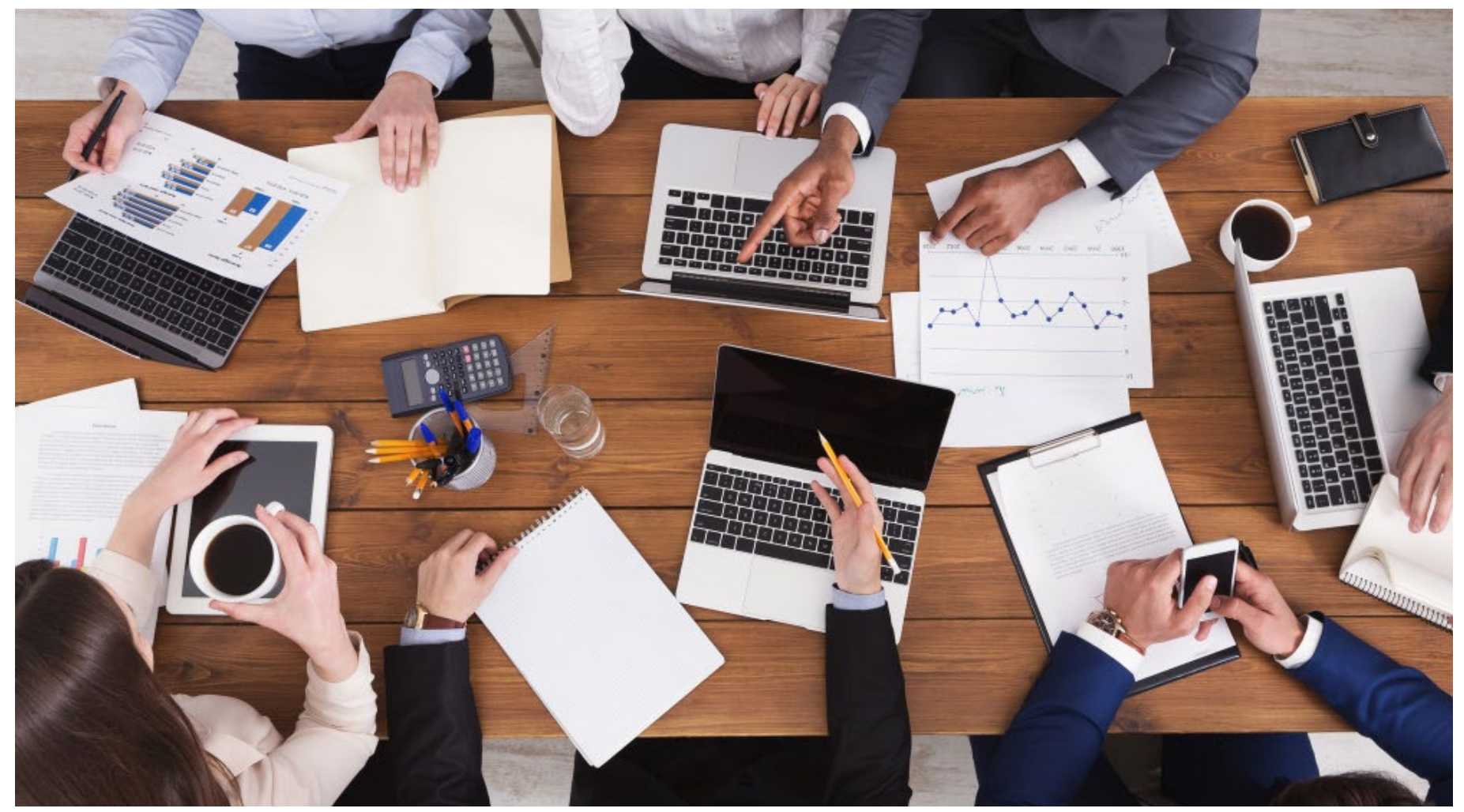

independiente de la lógica política, exigiéndoles que ejerzan su función de forma imparcial, objetiva y políticamente prescindente. Se trata de actuar con eficacia indiferente respecto del gobierno, en concordancia con el carácter profesional y técnico que les es propio y que no resulta compatible con el sistema de exclusiva confianza.

\section{Administración pública regional y municipal v/s órganos administrativos autónomos}

La propuesta también precisa que a la Administración Pública de carácter regional y municipal se le aplicarán los mismos principios, reconociéndose los mismos estamentos atribuidos a la administración central, sin perjuicio de mantener la flexibilidad que permite a las municipalidades crear o suprimir empleos y fijar remuneraciones, dentro de los límites y requisitos que determine la ley.

En cambio, no sería necesario reconocer dichos estamentos -pero sí los principiosen organismos administrativos constitucio- nalmente autónomos que no se encuentren sujetos a dirección o supervigilancia política, como pasa actualmente con la Contraloría General de la República o el Banco Central, pues no se produce en estos casos la confusión entre Gobierno y Administración!

De acogerse esta iniciativa, tras la aprobación de la nueva Constitución el legislador deberá adecuar la normativa vigente al nuevo marco, definiendo una organización básica de la Administración que facilite el cumplimiento del mandato constitucional.

Para ello se sugiere crear un órgano independiente responsable de dirigir la política de personas, monitorear el cumplimiento de las disposiciones legales que definan cada uno de los tres estatutos particulares y ejercer un rol rector respecto del funcionariado y de la Dirección Pública. No se propone consagrarlo directamente a nivel constitucional por considerar que la Constitución debe ser una norma de carácter general que contenga principios fundamentales y asumiendo, además, que tal como ahora se admitirá que el legislador pue- da crear organismos autónomos, tales como el Instituto de Derechos Humanos (INDH) o el Consejo para la Transparencia.

\section{Beneficios de la distinción entre el rol del Gobierno y la Administración Pública}

Establecer constitucionalmente la nítida división entre el rol de la Administración Pública y el del Gobierno facilitará la distinción entre políticas de Estado, que son concebidas para el largo plazo en respuesta a objetivos país, y las de Gobierno, cuyo ciclo se agota en el plazo de este. En nuestro país, la mayoría de los servicios públicos sectoriales, en los más variados ámbitos, ejecutan políticas públicas permanentes 0 de largo plazo, que trascienden los cambios de gobierno sin perjuicio, por supuesto, del deber funcionario de responder a las directrices ministeriales y ejecutar, con profesionalismo y neutralidad, las políticas gubernamentales.

La distinción también promueve la efectiva profesionalización de los estamentos directivos de la Administración, responsables de 
liderar los servicios públicos, quienes no deberían ser incluidos entre el personal de libre remoción gubernamental. En el 2003 se creó la Alta Dirección Pública. Significó un importante primer paso al apostar por optimizar la entrega de bienes y servicios a la ciudadanía y el cumplimiento de políticas y programas definidos por la autoridad, a través de la selección basada en los méritos de las y los postulantes a los equipos directivos del gobierno central.

Sin embargo, la decisión de entregar a la autoridad gubernamental la facultad de removerlos discrecionalmente -coherente con el exacerbado presidencialismo imperante-, debilita la formación de una gerencia pública profesional.

Aquello queda de manifiesto al constatar, tras sucesivos cambios de coalición gobernante, que con independencia de quien ocupe La Moneda cerca de dos tercios del personal directivo cesa en sus funciones durante los dos primeros años de gobierno por consideraciones fundamentalmente asociadas a la confianza política.

\section{Garantizar acceso igualitario al empleo público}

Para reforzar lo anterior, los/as firmantes de la propuesta señalan que la nueva Constitución no debiese limitarse a reconocer el derecho de todas las personas a acceder a todas las funciones y empleos públicos, sin otros requisitos que los que señalen la Constitución y las leyes, como lo hace la actual Carta Fundamental (art. $\left.19 \mathrm{~N}^{\circ} 17\right)$ e hicieron sus predecesoras.

Es preciso establecer, claramente, que el derecho fundamental a acceder a ellos sea en igualdad de oportunidades -salvo las excepciones que admita la propia Constitución, tales como los cargos de exclusiva confianza
0 los de elección popular-, respetando y promoviendo criterios de inclusión, no discriminación y equidad de género, de acuerdo con el tratamiento general que adopte en estos últimos temas la Convención Constitucional.

Además, debería precisarse que los sistemas de ingreso, desarrollo y cese en estas funciones y empleos, salvo las excepciones señaladas, deban respetar su carácter técnico y profesional, así como la dignidad de las personas. Lo anterior debería aplicarse a toda la Administración Pública e, incluso, a las funciones y empleos de otros órganos del Estado, como los legislativos y jurisdiccionales.

\section{Reconocimiento de los derechos colectivos de las y los trabajadores del estado sobre sindicalización, negociación colectiva y huelga}

Es evidente, por último, que no se puede soslayar la necesidad de eliminar las ac- tuales limitaciones al ejercicio de la negociación colectiva y la huelga que afectan a los trabajadores y trabajadoras del Estado, las que resultan anacrónicas en pleno siglo XXI, considerando, además, que nuestro país ha ratificado convenios internacionales que reconocen tales derechos.

Es por lo que se sugiere que la nueva Constitución admita los derechos colectivos para las/os trabajadoras/es del Sector Público en materia de sindicalización y negociación colectiva, además de aplicar las mismas normas que destina al sector privado respecto del derecho a huelga, salvo cuando se paralicen servicios esenciales 0 se impida la continuidad del servicio público en que regirá el procedimiento que establezca la ley. Además, estas disposiciones deberían aplicarse a los empleos de otros órganos del Estado, como los legislativos y jurisdiccionales. $\mathbf{E}$

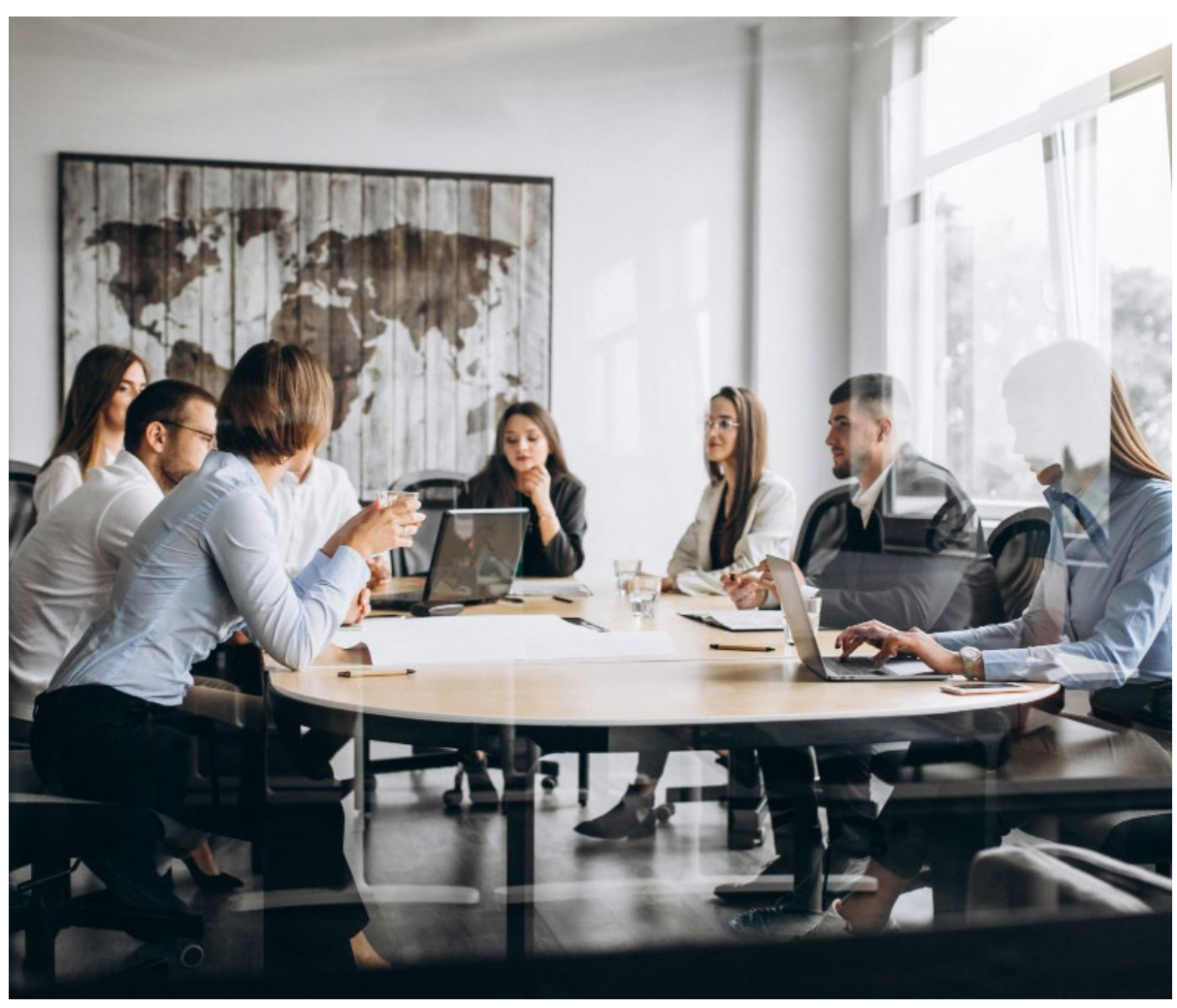

* Este texto y las propuestas que se exponen se basa en el documento "Propuesta constitucional para garantizar un servicio civil profesional e imparcial para Chile", que será presentado a la Convención Constitucional y que ha sido suscrito por más de un centenar de personas. Para acceder a su contenido y suscribirlo puede ingresarse a través del link https://forms.gle/EtFWeTdq4n8jc2hK8 